\title{
СПЕЦИФИКА КАРЬЕРНОЙ ПЕРСПЕКТИВЫ ЛИЧНОСТИ, ОКАЗАВШЕЙСЯ В СИТУАЦИИ БЕЗРАБОТИЦЫ
}

\author{
Анна Владимировна Курилова \\ инспектор \\ Центр занятости населения города Таганрога \\ 2. Таганрог, Россия \\ E-mail: tagszn@itt.net.ru
}

\section{Александр Леонидович Енин}

соискатель

Южный федеральный университет

2. Ростов-на-Дону, Россия

E-mail:enin1982@yandex.ru

\section{Таисия Эльбрусовна Гримсолтанова \\ педагог-психолог \\ Центр диагностики и консультирования \\ 2. Грозный, Россия \\ E-mail: tais.grimsoltanova@yahoo.com}

\section{Вера Михайловна Голубова}

кандидат психологических наук, дочент

Институт дружбы народов Кавказа

2. Ставрополь, Россия

E-mail:vera_led@rambler.ru

В статье дано психологическое понимание дефиниции «карьерная перспектива», представлены результаты теоретического и эмпирического исследования структурных компонентов карьерной перспективы безработных граждан.

Выявлено, что структурно карьерная перспектива субъекта деятельности определена ее ведущими компонентами:когнитивным (ментальные представления о профессиональной карьере), аффрективным (система отношений в прочессе планирования карьеры), поведенческим (разнонаправленные действия для достижения развития в карьере), мотивационным (мотивы профессиональной карьеры), ценностным (ценностные ориентации профессиональной карьеры). 
В статье представлена модель карьерной перспективы, основным критерием развития/наличия которой выступает степень сформированности ее структурных компонентов. Анализ характера представлений респондентов о карьерной перспективе позволил эмпирически выделить 4 базовых типа: полностью сформированная, частично сформированная, недостаточно сформированная, несформированная карьерная перспектива.

Для достижения поставленной чели настоящего исследования разработана авторская анкета, направленная на изучение структурных компонентов карьерной перспективы.

Проведен коррелячионный анализ компонентов карьерной перспективы безработных граждан. Формируется вывод о том, что карьерная перспектива безработных граждан, как один из прочессов, связанных с планированием карьеры, имеет свои специфические особенности.

В ходе исследования выявлено, что карьерная перспектива безработных граждан связана с реализацией индивидуальных ценностей, направленных на поддержание здоровья, общения и любви. Планирование карьерной перспективы безработными гражданами происходит на относительно близкий временной срок. У безработных преобладают недостаточно сформированная и несформированная карьерные перспективы, которые основаны на мотивачии избегания неудач, ориентации на прошлом и упомянутых ченностях. Выраженная сформированная карьерная перспектива характерна только $4 \%$ безработных граждан.

Ключевые слова: карьерная перспектива, карьера, профессиональная карьера, образ карьеры, планирование карьеры, карьерные чели, карьерные ориентации, жизненная перспектива, безработные граждане, безработица.

Для цитирования: Курилова А. В., Енин А. Л., Гримсолтанова Т. Э., Голубова В. М. Специфика карьерной перспективы личности, оказавшейся в ситуации безработицы // Российский психологический журнал. - 2016. T. 13. - № 3. - C. 26-38.

\title{
THE SPECIFICITY OF THE CAREER PROSPECTS OF PERSONS WHO FIND THEMSELVES IN A SITUATION OF UNEMPLOYMENT
}

\author{
Anna Vladimirovna Kurilova \\ Inspector \\ Center of employment of the population of Taganrog \\ Taganrog, Russia \\ E-mail: tagszn@itt.net.ru
}




\section{Aleksandr Leonidovich Enin}

Applicant

Southern Federal University

Rostov-on-Don, Russia

E-mail:enin1982@yandex.ru

\section{Taisiia El'brusovna Grimsoltanova}

Pedagogue-Psychologist

Diagnostics and Counseling Center

Grozny, Russia

E-mail: tais.grimsoltanova@yahoo.com

Vera Mikhailovna Golubova

Candidate of Psychology, Associate Professor Institute of the Caucasus People's Friendship

Stavropol, Russia

E-mail:vera_led@rambler.ru

The article provides psychological understanding of the definition of "career prospects" and presents the results of a theoretical and empirical study of structural components of the career prospects of the unemployed.

The carried out study revealed the following main structural components of career prospects of the person: cognitive (mental representations of professional career); affective (the system of relations in the career planning process), behavioral (multidirectional actions to achieve career development); motivational (motives of professional career), value (value guidelines of professional career).

The paper presents a model of career prospects. The degree of formation of structural components of this model is the main criterion of its development/ presence. The analysis of the respondents' representations of career prospects made it possible to distinguish four basic types of prospects: fully formed, partially formed, insufficiently formed, and unformed ones.

To achieve the objectives of the present study the authors developed a questionnaire aimed at studying the structural components of career prospects.

The authors carried out the correlation analysis of the components of the career prospects of the unemployed and drew a conclusion about specific features of career prospects of the unemployed as one of the processes related to career planning.

The study revealed that the career prospects of the unemployed relates to the implementation of individual values of the maintenance of health, communication, and love. The unemployed planned their career prospects for a relatively near time 


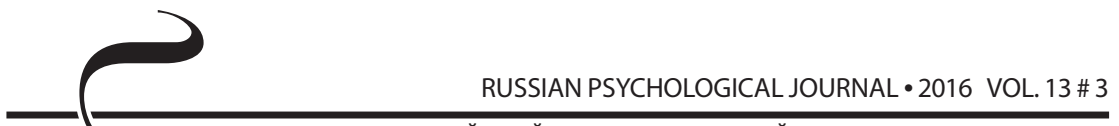

РОССИЙСКИЙ ПСИХОЛОГИЧЕСКИЙ ЖУРНАЛ • 2016 ТОМ 13 № 3

period. The insufficiently formed and unformed career prospects, which were based on the motivation to avoid failure and orientation on the past and the abovementioned values, were dominant in the unemployed. Only $4 \%$ of the unemployed had the formed career perspects.

Keywords: career prospects, career, professional career, career image, career planning, career goals, career orientation, life perspective, unemployed citizens, unemployment.

For citation: Kurilova A. V., Enin A. L., Grimsoltanova T. E., Golubova V. M. The Specificity of the Career Prospects of Persons Who Find Themselves in a Situation of Unemployment. Russian Psychological Journal, 2016, V. 13, no. 3, pp. 26-38.

\section{Введение}

На сегодняшний день способность человека планомерно выстраивать личный карьерный путь выступает одной из наиболее значимых по ряду причин.

В условиях непрерывной смены социальной, экономической и политической действительности России происходят уместные трансформации, сказывающиеся на структуре, объеме занятости населения. В такой жизненной ситуации личностно зрелый человек стремится адаптироваться к постоянно изменяющимся условиям современного рынка труда страны, заблаговременно изменяя содержание личной карьерной перспективы. Ежедневно меняется социальная структура общества, существенны изменения и в самом качестве социальных проблем, но наличие рабочего места, возможность планомерного выстраивания профессионального и карьерного будущего остаются важнейшим навыком социальной активности, а для многих и профессиональным кредо- назначением и смыслом жизни.

Помимо внешних обстоятельств современной жизни, в процессе выстраивания карьеры субъектом многократно меняются и его индивидуальные карьерные цели, в частности карьерные ориентации, сам образ карьеры, которые идеальным итогом имеют результаты: достижение статусно-ролевых позиций и/или развитие личности, смена материального статуса, уважение и др.

\section{Актуальность исследования}

Так или иначе, в кризисной ситуации потери работы далеко не каждый человек способен к своевременному принятию кардинальных решений в новых жизненных обстоятельствах, когда на протяжении определенного временного отрезка профессиональное и карьерное будущее было предопределено уже привычным «трудовым укладом». В ситуации сокращения штатной единицы, по причине несформированной готовности к смене 
рабочего места, а в иных случаях и сферы профессиональной деятельности, отсутствия актуального карьерного плана-особенно тяжело протекает социальная адаптация безработных граждан [3].

Следовательно, исследование планирования карьеры безработными гражданами представляет значительный научный интерес в силу ценного прогнозирования состояния, структуры и уровня безработицы в Российской Федерации, так и для проведения психологической поддержки данной категории граждан с целью восстановления их активного профессионального статуса через процесс планирования карьерной перспективы и целеполагания.

Таким образом, целью исследования выступает изучение структурных компонентов карьерной перспективы безработных граждан. Объектом исследования выступает карьерная перспектива, предметом-когнитивный, аффективный, мотивационный, ценностный, поведенческий компоненты карьерной перспективы безработных граждан. Гипотеза исследования карьерная перспектива безработных граждан недостаточно сформирована, что затрудняет активный поиск работы данной категорией граждан.

Рандомизированная выборка безработных граждан представлена респондентами, зарегистрированными в ГКУ РО «Центр занятости населения города Таганрога», направленными на профконсультирование к специалистам-психологам с целью профориентации, профотбора, психологической поддержки или социальной адаптации в количестве 50 человек (31 женщина и 19 мужчин), в возрасте от 21 года до 52 лет.

\section{Теоретическая значимость исследования}

Сравнительный анализ представленной в психологической научной литературе дефиниции «карьера» показал, что «карьера» понимается как «многоаспектный, многомерный, развиваемый личностью и развивающий ее феномен; неразрывно связанный с социализацией и развитием личности профессиональный путь, который реализуется на всех этапах ее субъектом и характеризуется с точки зрения ее целей и средств, содержания и формы, процесса и результата, возможности развития ее субъекта» [9, с. 189].

Процесс планирования карьеры напрямую связан с психологическим термином «карьерная перспектива». В современном поле акмеологии данный термин не разрабатывался и не использовался как отдельный психологический концепт, что и обуславливает своевременность изучения представлений о карьерной перспективе личности, в том числе и оказавшейся в ситуации потери работы.

Анализ имеющихся работ по планированию и проектированию будущей карьеры, образа карьеры (П. Б. Бондарев, Е. И. Головаха, 
С. Т. Джанерьян, А. Я. Кибанов, Н. Л. Кирт, Е. М. Кочнева, И. П. Лотова, Е. Г. Молл, И. А. Панкратова, Э. Е. Толгурова, Я. А. Чернышов, А. М. Шевелева, B. K. Шеповалов, J. D. Krumboltz, F. W. Vondracek) позволил выделить и определить понятие «карьерная перспектива» $[6,7,9,11]$.

В рамках настоящего исследования карьерная перспектива рассматривается как многомерное образование, отражающее динамичные представления карьерного будущего, интеграцию первоочередных и второстепенных планов профессионально-личностного становления, альтернативные пути их реализации в процессе развития карьеры субъектом [8].

Исходя из основ системного подхода (Л. С. Выготский, Б. Ф. Ломов, К. К. Платонов, С. Л. Рубинштейн), карьерная перспектива формируется в соответствии с особенностями жизненной перспективы (локализация, структура, качественные характеристики, содержательные компоненты, параметры) и является ее проявлением [5].

Структурно карьерная перспектива представлена когнитивным (ментальные представления о профессиональной карьере), аффективным (система отношений в процессе планирования карьеры), поведенческим (разнонаправленные действия для достижения развития в карьере), мотивационным (мотивы профессиональной карьеры), ценностным (ценностные ориентации профессиональной карьеры) компонентами. Теоретико-методологической основой описания структурных компонентов карьерной перспективы выступили: психологическая теория личности и деятельности С. Л. Рубинштейна и А. Н. Леонтьева, концепция личности как субъекта жизнедеятельности К. А. Абульхановой-Славской, концепция отношений личности (В. Н. Мясищев, Н. И. Сарджвеладзе), иерархическая модель потребностей А. Маслоу, а также теория фундаментальных эмоций К. Э. Изарда.

Основными параметрами карьерной перспективы выступают: продолжительность, реалистичность, дифференцированность, оптимистичность, согласованность [18]. Анализ содержания карьерной перспективы позволил выявить основные функции феномена, а именно: мотивообразование, целеполагание, смыслообразование, мобилизацию и планирование $[1,2,7]$.

Содержание компонентов карьерной перспективы определено через высокий/низкий уровни мотивации к достижению успеха, мотивации избегания неудач (мотивационный); наличие/отсутствие ценностных ориентаций в карьере (ценностный); представления о карьерной перспективе и способности к ее планированию во времени, направленность на будущее (когнитивный); личностную ориентацию «на дело» по Б. Бассу (поведенческий); ведущие эмоции при планировании карьерной перспективы (аффективный). 
Исходя из особенности распределения респондентов, основным критерием развития карьерной перспективы выступает степень сформированности ее содержательных компонентов. Проведенный анализ характера представлений респондентов о карьерной перспективе позволил теоретически выделить ее 4 основополагающих типа (рисунок 1).

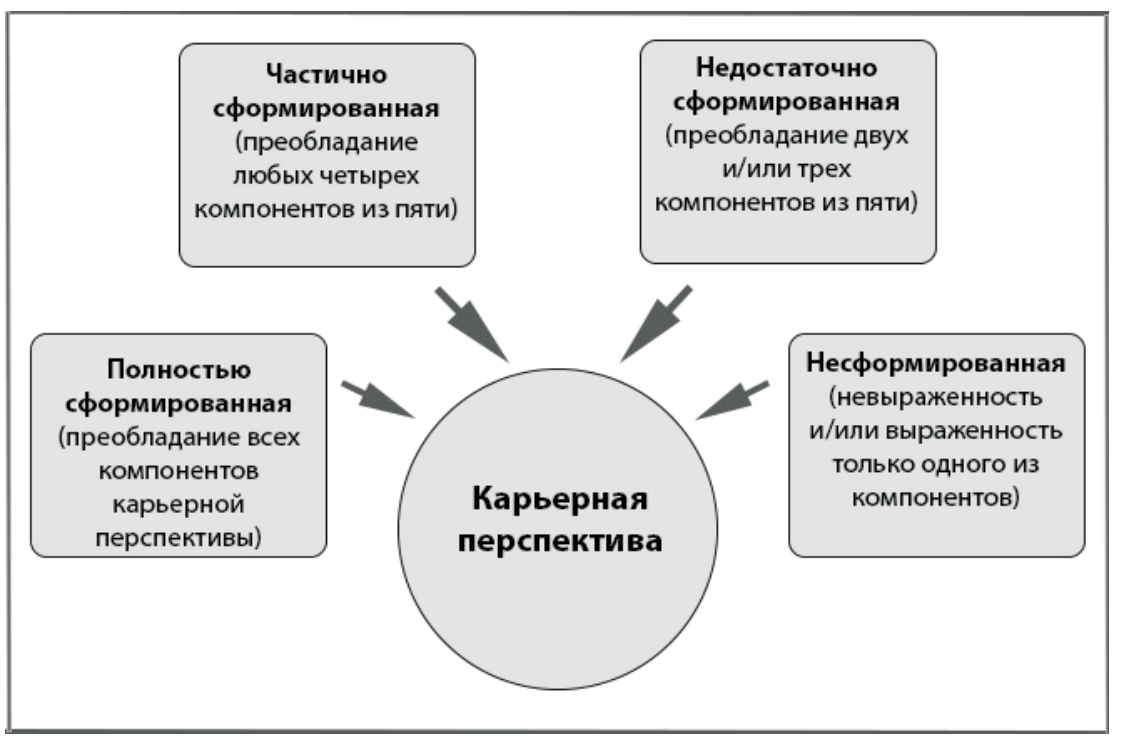

Рисунок 1. Типы карьерной перспективы

\section{Методы и методики исследования}

1. Анкетирование (авторская анкета, направленная на изучение содержания компонентов карьерной перспективы субъектов деятельности (С. Т. Джанерьян, И. Ф. Демидова, А. В. Курилова)).

2. Психологическое тестирование (опросник временной перспективы Ф. Зимбардо (ZPTI) [14, 20], методика диагностики личности на мотивацию к успеху Т. Элерса, методика диагностики на мотивацию к избеганию неудач Т. Элерса, методика диагностики направленности личности (ориентационная анкета) Б. Басса, методика диагностики реальной структуры ценностных ориентаций личности С. С. Бубнова).

3. Метод контент-анализа для обработки полученной информации на «открытые» вопросы анкеты.

4. Метод статистической обработки данных-коэффициент ранговой корреляции $\mathrm{r}^{\mathrm{s}}$ Спирмена. 


\section{Результаты}

Карьерная перспектива понимается безработными гражданами как: 1) «карьерный рост»; 2) «возможность»; 3) «повышение квалификации/ разряда»; 4) «новая работа». Безработные задумываются о карьерной перспективе каждый день в 23,5\% случаев, в 11,7\% случаев-каждую неделю, 35,2\%-несколько раз в месяц, каждый месяц планируют 11,7\%, и раз в год $-17,9 \%$.

Мотивация избегания неудач составила $m=18,04$, мотивация к успеху $\mathrm{m}=14,88$. Направленность личности «на себя» составила $60 \%$, «на дело»$34 \%$, и «на общение»- $6 \%$.

Из предложенных ценностей анкеты предпочитаемыми в данной выборке стали: 1) «конкретные жизненные ценности» (здоровье, работа, друзья, семейная жизнь, общение), $\mathrm{m}=8,91 ; 2$ ) «пассивные ценности» (красота природы и искусства, уверенность в себе, познание, жизненная мудрость), $\mathrm{m}=8,5 ; 3$ ) «ценности межличностных отношений» (наличие друзей, счастливая семейная жизнь, счастье других), $m=7,88$.

При построении карьерной перспективы безработные граждане испытывают эмоции: 1$)$ интерес $(\mathrm{m}=4,91) ; 2)$ печаль $(\mathrm{m}=4,34) ; 3)$ радость $(\mathrm{m}=3,5)$; 4) удивление $(m=3,22) ; 5)$ страх $(m=2,76)$.

Сформированность карьерной перспективы в группе безработных граждан представлена результатами: полностью сформированная карьерная перспектива в $4 \%$ случаев, частично сформированная в $20 \%$ случаев, недостаточно сформированная в $44 \%$ случаев, и несформированная карьерная перспектива выражена у $30 \%$ безработных.

Результаты корреляционного анализа позволили прийти к следующим выводам. Мотивация достижения успеха находится в прямой корреляции с ценностью «познание нового в мире, природе, человеке» ( $r s=0,520$, при $\mathrm{p} \leq 0,01)$ и временной шкалой «будущее» ( $r s=0,369$, при $\mathrm{p} \leq 0,01)$. В свою очередь, мотивация избегания неудач положительно соотносится с ценностями «высокое материальное благосостояние» (rs =0,314, при $\mathrm{p} \leq 0,05)$, «поиск и наслаждение прекрасным» ( $r s=0,327$, при $\mathrm{p} \leq 0,05)$.

Направленность на себя (Я) соотносится положительной корреляционной связью с ценностями: «любовь» ( $r s=0,308$, при $p \leq 0,05)$, «общение» ( $r s=0,590$, при $p \leq 0,01)$, «здоровье» ( $r s=0,444$, при $p \leq 0,01)$; отрицательной с ценностями: «помощь и милосердие к другим людям» (rs = -0,391, при $\mathrm{p} \leq 0,01)$, «познание нового в мире, природе, человеке» ( $r s=-0,335$, при $\mathrm{p} \leq 0,05)$ и временной шкалой «будущее» ( $r s=-0,408$, при $\mathrm{p} \leq 0,01)$. Направленность на общение (O) положительно коррелирует с ценностью «помощь и милосердие к другим людям» ( $\mathrm{rs}=0,297$, при $\mathrm{p} \leq 0,05$ ) и с временной шкалой «фаталистическое настоящее» (rs =0,330, при 
p $\leq$ 0,05), отрицательно - с ценностью «социальная активность для достижения позитивных изменений в обществе» ( $r s=-0,294$, при $p \leq 0,05)$. Направленность на дело (Д) находится в прямой корреляции с ценностью «познание нового в мире, природе, человеке» ( $r s=0,281$, при $p \leq 0,05)$ и временными шкалами «будущее» ( $r s=0,365$, при $p \leq 0,01)$ и «позитивное прошлое» (rs = 0,311, при $\mathrm{p} \leq 0,05)$; в обратной корреляции - с ценностями: «высокое материальное благосостояние» ( $r s=-0,290$, при $\mathrm{p} \leq 0,05$ ), «признание и уважение людей и влияние на окружающих» (rs =-0,356, при $p \leq 0,05)$, «общение» ( $r s=-0,461$, при $p \leq 0,01)$, «здоровье» ( $r s=-0,407$, при $\mathrm{p} \leq 0,01)$.

Временная шкала «будущее» соотносится с ценностями «помощь и милосердие к другим людям» ( $r s=0,458$, при $p \leq 0,01)$, «познание нового в мире, природе, человеке» ( $r s=0,331$, при $\mathrm{p} \leq 0,05)$, «здоровье» ( $\mathrm{s}=-0,411$, при $\mathrm{p} \leq 0,01)$. Шкала «негативное прошлое» положительно коррелирует с ценностью «высокий социальный статус и управление людьми» (rs = 0,399, при $\mathrm{p} \leq 0,01)$. Шкала «гедонистическое настоящее» соотносится с ценностями: «высокое материальное благосостояние» (rs $=-0,351$, при $\mathrm{p} \leq 0,05)$, «высокий социальный статус и управление людьми» (rs = -0,331, при $\mathrm{p} \leq 0,05)$, «признание и уважение людей и влияние на окружающих» ( $r s=0,329$, при $p \leq 0,05)$. Шкала «позитивное прошлое» соотносится с ценностью «высокое материальное благосостояние» ( $r s=-0,437$, при $p \leq 0,05)$. Шкала «фаталистическое настоящее» коррелирует с ценностями «приятное времяпрепровождение, отдых» ( $r s=0,364$, при $p \leq 0,01)$, «общение» ( $r s=-0,356$, при $p \leq 0,05)$.

\section{Выводы}

Следовательно, карьерная перспектива безработных граждан выражена в пяти компонентах.

В ментальных представлениях (когнитивный компонент) безработных граждан присутствует понимание, что реализация карьерной перспективы возможна и логична только при наличии самой карьеры, поэтому наличие данной ассоциации в таких представлениях, как «новая работа», неслучайно.

В данной группе при построении карьерной перспективы выражена мотивация избегания неудач (мотивационный компонент), которая выступает своего рода барьером к планированию карьеры.

Выраженная личностная ориентация на себя указывает на такую поведенческую особенность (поведенческий компонент), при которой безработные граждане ориентированы на решение собственных потребностей и проблем, вознаграждение безотносительно к вложенным усилиям, что еще раз подтверждается и такими доминирующими ценностными 
ориентациями (ценностный компонент) в данной группе респондентов, как здоровье, работа, друзья, семейная жизнь, общение.

При планировании личной карьерной перспективы безработные граждане предпочтительно испытывают эмоцию «интерес» (аффективный компонент), характеризующую познавательную потребность в процессе планирования будущего.

Таким образом, безработные граждане при построении карьерной перспективы в большей степени ориентированы на реализацию индивидуальных ценностей, что подтверждается и такой переориентацией на мотивацию избегания неудач, как уход от социальной активности в сторону созерцания прекрасного (одна из возможных защитных реакций на стресс, вызванный наличием свободного времени). В планах на будущее отсутствует ориентация на достижение карьерных целей, представители категории обеспокоены состоянием здоровья, хотели бы оказывать помощь другим, интеллектуально развиваться.

Подводя итоги исследования, стоит отметить, что несформированная карьерная перспектива безработных граждан играет не последнюю роль в планировании карьеры, социальной адаптации к условиям современного рынка труда, затрудняя процесс профессионализации. Можно предположить, что сложности в построении карьерной перспективы сказываются не только на актуальном поиске работы в настоящем, но и, возможно, привели к потере рабочего места в прошлом.

Данная исследовательская работа вносит вклад в совершенствование профессионального консультирования безработных граждан, а также служит отправной точкой для разработки психологической тренинговой программы сотрудниками-профконсультантами в системе занятости населения, направленной на активизацию процессов целеполагания и долгосрочного планирования карьеры клиентами.

\section{Литература}

1. Абульханова К. А., Березина Т. Н. Время личности и время жизни. -СПб.: Алетейя, 2001.

2. Абульханова-Славская К. А. Стратегия жизни. - М., 1991.

3. Бендюков М. А. Психология профессионального кризиса у безработных: автореф. дисс. ... д. психол. наук. -СПб., 2009.

4. Васильев В.Я. Целевая направленность и временная перспектива личности // Психология личности и время жизни человека. - Черновцы, 1991.

5. Выготский Л. С. О психологических системах // Выготский Л. С. Собрание сочинений: в 6 т. - М., 1984. - Т. 6. 
6. Головаха Е. И. Жизненные перспективы и ценностные ориентации личности // Психология личности в трудах отечественных психологов. - СПб., 2001.

7. Головаха Е. И., Кроник А. А. Психологическое время личности. - М.: Смысл, 2008.

8. Демидова И. Ф., Курилова А. В. Представления студентов о карьерных перспективах // Вестник Таганрогского института управления и экономики. Научно-теоретический и информационно-методический журнал. - 2014. - 1 (19). - С. 109-111.

9. Джанерьян С. Т. Профессиональная Я-концепция: системный анализ. Ростов н/Д: Изд-во Рост. Ун-та, 2004. - 480 с.

10. Кулагина И. Ю., Колюцкий В. Н. Возрастная психология: Полный жизненный цикл развития человека. - М.: Сфера, 2001.

11. Мандрикова Е. Ю. Современные подходы к изучению временной перспективы личности // Психологический журнал. - 2008. - Т. 29. - № 4.

12. Маркова А. К. Психология профессионализма. - М.: Знание, 1996.

13. Серенкова В. Ф. Личностная организация времени как средство реализации жизненных планов // Применение концепции С. Л. Рубинштейна в разработке вопросов общей психологии. - М., 1989.

14. Сырцова А. Адаптация опросника временной перспективы личности Ф. Зимбардо // Психологический журнал. - 2008. - Т. 29. - 3. C. 101-109.

15. Cottle T. J., Klineberg S. L. The Present of Things Future: Exploration of Time in Human Experience. - N. Y., 1974.

16. Fraisse P. Psychologie du Temps. - P., 1957.

17. Frank L. K. Time Perspective // Journal of Social Philosophy. - 1939. - no. 4.

18. Nuttin J., Lens W. Future Time Perspective and Motivations: Theory and Research Method. - N. J., 1985.

19. Zaleski Z. Personal Future in Hope and Anxiety Perspective // Psychology of Future Orientation / Z. Zaleski (Ed.). - Lublin, 1994.

20. Zimbardo P. G. A New Perspective on Psychological Time: Theory, Research and Assessment of Individual Differences in Temporal Perspective // Mucciarelli G., Brigati R. Psychology of Time. Part 2. Special Issues, Theory \& Modeli. - 1998. - no. 3.

\section{References}

1. Abul'khanova K. A., Berezina T. N. Vremia lichnosti i vremia zhizni [The time of personality and the time of living]. St. Petersburg, Aleteiia Publ., 2001.

2. Abul'khanova-Slavskaia K. A. Strategiia zhizni [A life strategy]. Moscow, 1991. 
3. Bendiukov M. A. Psikhologiia professional'nogo krizisa u bezrabotnykh. Diss. kand.psikh. nauk [The psychology of professional crisis of the unemployed. Cand. psych. sci. diss]. St. Petersburg, 2009.

4. Vasil'ev V. la. Tselevaia napravlennost' i vremennaia perspektiva lichnosti [Goal orientation and time perspective of the person]. Psikhologiia lichnosti i vremia zhizni cheloveka - Personality Psychology and Life Time of a Person, Chernovtsy, 1991.

5. Vygotskii L. S. O psikhologicheskikh sistemakh [On psychological systems]. Moscow, 1984.

6. Golovakha E. I. Zhiznennye perspektivy i tsennostnye orientatsii lichnosti: Psikhologiia lichnosti v trudakh otechestvennykh psikhologov [Life prospects and value orientations of the person: Personality psychology in works of Russian psychologists]. St. Petersburg, 2001.

7. Golovakha E. I., Kronik A. A. Psikhologicheskoe vremia lichnosti [Psychological time of personality]. Moscow, Smysl Publ., 2008.

8. Demidova I. F., Kurilova A. V. Predstavleniia studentov o kar'ernykh perspektivakh [Students' representations about career prospects]. Vestnik Taganrogskogo instituta upravleniia i ekonomiki. Nauchno-teoreticheskii i informatsionno-metodicheskii zhurnal - Bulletin of Taganrog Institute of Management and Economics, 2014, 1 (19), pp. 109-111.

9. Dzhaner'ian S. T. Professional'naia la-kontseptsiia: sistemnyi analiz [Professional self-concept: system analysis]. Rostov-on-Don, Rostov State University Publ., 2004. 480 p.

10. Kulagina I. lu., Koliutskii V. N. Vozrastnaia psikhologiia: Polnyi zhiznennyi tsikl razvitiia cheloveka [Developmental psychology: the full life cycle of human development]. Moscow, Sfera Publ., 2001.

11. Mandrikova E. lu. Sovremennye podkhody k izucheniiu vremennoi perspektivy lichnosti [Modern approaches to studying the temporal perspective of personality]. Psikhologicheskii zhurnal-Psychological Journal, 2008, V. 29, no. 4.

12. Markova A. K. Psikhologiia professionalizma [The psychology of professionalism]. Moscow, Znanie Publ., 1996.

13. Serenkova V. F. Lichnostnaia organizatsiia vremeni kak sredstvo realizatsii zhiznennykh planov: Primenenie kontseptsii S. L. Rubinshteina v razrabotke voprosov obshchei psikhologii [Personal time management as a means of implementation of life plans: application of S. L. Rubinstein's concept in the elaboration of general psychology issues]. Moscow, 1989.

14. Syrtsova A. Adaptatsiia oprosnika vremennoi perspektivy lichnosti F. Zimbardo [Adaptation of the questionnaire of the temporal perspective of personality F. Zimbardo]. Psikhologicheskii zhurnal - Psychological Journal, 2008, V. 29, no. 3, pp. 101-109. 
RUSSIAN PSYCHOLOGICAL JOURNAL • 2016 VOL. 13 \# 3

15. Cottle T. J., Klineberg S. L. The Present of Things Future: Exploration of Time in Human Experience. N. Y., 1974.

16. Fraisse P. Psychologie du Temps. P., 1957.

17. Frank L. K. Time Perspective. Journal of Social Philosophy, 1939, no. 4.

18. Nuttin J., Lens W. Future Time Perspective and Motivations: Theory and Research Method. N. J., 1985.

19. Zaleski Z. Personal Future in Hope and Anxiety Perspective. Psychology of Future Orientation. Z. Zaleski (Ed.). Lublin, 1994.

20. Zimbardo P. G. A New Perspective on Psychological Time: Theory, Research and Assessment of Individual Differences in Temporal Perspective. Mucciarelli G., Brigati R. Psychology of Time. Part 2. Special Issues, Theory \& Modeli, 1998, no. 3. 